\title{
The role of RNA-binding protein, microRNA and alternative splicing in seed germination: a field need to be discovered
}

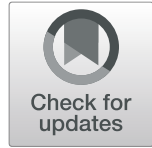

\author{
Xiaofei Xue ${ }^{1 \dagger}$, Fuchao Jiao ${ }^{1,2 \dagger}$, Haicheng $X^{3}$, Qiqing Jiao ${ }^{4}$, Xin Zhang ${ }^{5}$, Yong Zhang ${ }^{6}$, Shangyi Du', Menghan Xi', \\ Aiguo Wang ${ }^{1}$, Jingtang Chen ${ }^{1,2}$ and Ming Wang ${ }^{1,2^{*}}$ (D)
}

\begin{abstract}
Seed germination is the process through which a quiescent organ reactivates its metabolism culminating with the resumption cell divisions. It is usually the growth of a plant contained within a seed and results in the formation of a seedling. Post-transcriptional regulation plays an important role in gene expression. In cells, post-transcriptional regulation is mediated by many factors, such as RNA-binding proteins, microRNAs, and the spliceosome. This review provides an overview of the relationship between seed germination and post-transcriptional regulation. It addresses the relationship between seed germination and RNA-binding proteins, microRNAs and alternative splicing. This presentation of the current state of the knowledge will promote new investigations into the relevance of the interactions between seed germination and post-transcriptional regulation in plants.
\end{abstract}

Keywords: Seed germination, RNA-binding protein, microRNA, Alternative splicing

\section{Background}

A seed is a grain or ripened ovule of a plant that is used for sowing, and it is considered a condensed form of the plant. Under suitable environmental conditions, it can germinate from a physiological quiescence status, mobilize its reserves, biosynthesize new proteins, regenerate organelles, and produce cell membranes, eventually protruding the radicle and entering seedling establishment. Seed germination refers to a series of physiological and morphogenetic processes, which activates many new biological processes, including DNA replication, enzyme activation, cell division, membrane and mitochondrial repair, protein synthesis, generation of a sufficient energy supply, seedling growth $[1,2]$. In dicotyledons, the

\footnotetext{
* Correspondence: ming.wang@qau.edu.cn

${ }^{+}$Xiaofei Xue and Fuchao Jiao are co-first authors.

${ }^{1}$ College of Agronomy, Qingdao Agricultural University, Qingdao 266109, China

${ }^{2}$ Dryland-Technology Key Laboratory of Shandong Province, Qingdao Agricultural, Qingdao 266109, China

Full list of author information is available at the end of the article
}

embryonic root first emerges from the seed. It can make the seedling anchor in the ground. After water absorbing, an embryonic shoot emerges from the seed $[3,4]$. In monocotyledons seeds, the embryo's cotyledon and radicle are covered by a coleoptile and coleorhiza, respectively. The coleorhiza grows out of the seed first, followed by the radicle. The coleoptile is then pushed up until it reaches the surface $[3,4]$. The regulatory network of seed germination is mediated by many factors, e.g., temperature, water, oxygen, light, nutrition, phytohormones, and mRNA oxidation [5-8].

Post-transcriptional regulation refers to the regulation of gene expression at post-transcriptional level. It plays an important role in regulating gene expression [9-11]. The expression of the different genes is posttranscriptionally regulated by many factors, such as RNA-binding proteins (RBPs), microRNAs (miRNAs), spliceosome [12-15]. RNA-binding proteins are proteins that act as important regulators of many processes such as alternative splicing, mRNA nuclear export, mRNA 
stability, and translation. RNA-binding protein can achieve these events through an RNA recognition motif (RRM) that allows binding of the RNA-binding protein to a secondary structure or specific sequence in their target transcripts. RNA-binding proteins play a pivotal role in post-transcriptional regulation of different RNAs, such as splicing, mRNA stability, polyadenylation, mRNA localization [11, 16, 17]. microRNAs (miRNAs) also participate in the post-transcriptional regulation of gene expression. miRNA is a type of endogenous small non-coding RNA molecule with a length of about 20-24 nucleotides, which has many important regulatory functions in cells. Each miRNA can have multiple target genes, and even several miRNAs can also pair with the same target gene $[14,18]$. miRNAs can influence the translation of the mRNA, drive mRNA cleavage or shorten the poly(A) tail $[19,20]$. Alternative splicing is mediated by the spliceosome. The spliceosome is a kind of large and complex molecular machine within the nucleus of cells [21]. It mainly participates in mRNA processing by removing introns from a transcribed premRNA [22]. Splicing can also generate the premature stop codons that recruit the NMD (nonsense mediated decay) machinery $[21,23]$. The proteins translated from alternatively spliced mRNAs would have different amino acid sequence. Consequently, the protein structure and biological functions would be changed. Posttranscriptional regulation is also reflected in the splicing and processing of the mRNA precursor hnRNA, the process and positioning of the mRNA, the stability of the mRNA and its degradation, RNA editing.

Understanding the seed germination regulatory network can help us to better understand the situation of the seed itself and improve the germination rate of the seed and the development status of the seedling. This review addresses the relationship between seed germination and post-transcriptional gene regulation in plants. It provides insight into the role of some important mechanisms of post-transcriptional regulation: RNAbinding protein, miRNA and alternative splicing. We also raise some questions about future studies in the discussion section.

\section{Seed germination and RNA-binding proteins}

RNA-binding protein can bind to single stranded RNA or double stranded RNA in eukaryotic cells, and plays a key role in almost all aspects of post-transcriptional regulation [17, 24]. RNA-binding proteins are characterized by the presence of different RNA-binding domains, e.g. RNA recognition motif (RRM), K-homology (KH) domain, zinc finger structure, pentatricopeptide-repeat (PPR) domain [25-27]. In Arabidopsis, more than 200 different RNA-binding proteins were identified in the genome, and most of them were plant-specific, suggesting specific functions in plant physiology [24]. The relationship between RNA-binding proteins and seed germination has been examined in numerous studies. Narsai et al. (2011) carried out an in-depth transcriptomic profiling in Arabidopsis to investigate the regulatory mechanism of seed germination. More than 10,000 genes were differentially expressed during cold stratification, revealing an active period in preparing seeds for germination [28]. Among them, genes encoding proteins involved in RNA-binding functions, included RNA helicases, RNA-binding proteins, and ribonucleases, were identified in transcriptomic profiling. Further analysis showed that 137 PPR domaincontaining genes that have been shown to have roles in RNA splicing, cleavage, editing, stability, and translation displayed transient expression during germination, and of these, 75 genes showed germination-specific expression $[28,29]$. In addition, the presence of mitochondrial DNA replication factors and RNA-processing functions in this germination-specific subset represents the earliest events in organelle biogenesis, preceding any changes associated with energy metabolism. This result also suggested that the collaboration among RNA-binding proteins, the mitochondrial origin and retrograde signals may be crucial for successful seed germination [28].

In plants, abscisic acid (ABA) is an important negative regulator of seed germination [30]. In Arabidopsis, Jung et al. (2013) characterized an ABA-regulated RRMcontaining RNA-binding protein designated ARP1 (ABA-REGULATED RNA-BINDING PROTEIN 1) [31]. The experiment showed that ARP1 transcription was inhibited by ABA. Interestingly, both overexpression and knockdown arp1 mutants resulted in delayed seed germination under $\mathrm{ABA}$, high salt, and dehydration stress conditions. The identical phenotypes of the arp1-overexpressing mutant and the arp1 knockdown mutant indicated that tight regulation of the ARP1 transcript is necessary for normal germination. This result indicated that ARP1 affects ABA-regulated seed germination of Arabidopsis through post-transcriptional regulation [31]. In addition, MCT1 (MEI2 C-TERMINAL RRM ONLY LIKE 1) is another ABA related RRM containing protein in Arabidopsis. The study from Gu et al. (2016) showed that the transcript level of MCT1 was markedly increased upon ABA treatment [32]. Further analysis of MCT1-overexpressing mutant and mct1 knockdown mutants demonstrated that MCT1 inhibited seed germination under ABA treatment. Moreover, the transcript levels of $A B I 3, A B I 4$, and $A B I 5$, three $\mathrm{ABA}$ signaling-related genes, were increased by MCT1 [32]. Previous research indicated that $A B I 3, A B I 4$, and $A B I 5$ play a negative role in seed germination in Arabidopsis [33-37]. These studies showed that ABA-upregulated MCT1 plays a negative role in seed germination under 
ABA by modulating the expression of $\mathrm{ABA}$ signalingrelated genes. Besides, abiotic stresses act as important effectors of seed germination, and they regulate seed germination through ABA [38, 39]. Various abiotic stress-related RNA-binding proteins have been determined to perform crucial roles in post-transcriptional regulation of RNA metabolism during seed responses to abiotic stresses. Studies examining glycine-rich RNAbinding proteins have indicated an important role for these proteins during Arabidopsis germination under abiotic stresses [40].

GLYCINE RICH PROTEIN 2 (GRP2) is a glycine-rich RNA-binding protein. Fusaro et al. (2007) demonstrated that AtGRP2 expression is regulated by cold in Arabidopsis [41]. Expression analysis revealed that the AtGRP2 gene is active in meristematic tissues. Downregulation of the AtGRP2 gene using gene-silencing techniques resulted in early flowering and an altered stamen number, and it affected seed development [41]. Further study indicated that AtGRP2 is a nucleocytoplasmic protein characterized by a nucleic acid-binding CSD domain, two glycine-rich domains and two $\mathrm{CCHC}$ zincfingers [42]. AtRZ-1a encodes a zinc finger-containing glycine-rich RNA-binding protein, and it has a negative impact on seed germination in Arabidopsis under salt or drought stress conditions [40]. Researchers showed that overexpressing the atRZ-1a mutant resulted in higher $\mathrm{H}_{2} \mathrm{O}_{2}$ levels and retarded germination compared with the wild type under salt or dehydration conditions. In contrast, the knockdown mutants of atRZ-1a germinated earlier under the same stress conditions. Moreover, germination of the transgenic plants and mutant lines was influenced by the addition of ABA. Furthermore, the research also showed that the transcription level of several genes, such as ISO (isocitrate lyase), CRU (cruciferin), SSP (12S seed storage protein) and LEAP (LEA protein in group five), were induced in the atRZ$1 a$-overexpressing mutant. Moreover, further proteome analysis identified the putative target genes of atRZ-1a, including ferredoxin-nitrate reductase, aconitate hydratase, glyceraldehyde 3-phosphate dehydrogenase, alcohol dehydrogenase, phosphoglycerate mutase, thylakoid lumenal protein, glutathione reductase, glutathione Stransferase, glutamate 1-semialdehyde aminomutase, carbonic anhydrase, and serine hydroxymethyl transferase [40]. This analysis revealed that the genes involved in reactive oxygen species homeostasis (important for seed germination, [43, 44]) were affected by atRZ-1a during seed germination (Fig. 1).

In addition, Park et al. (2017) investigated the functional roles of three zinc-finger RNA-binding proteins (RZs) in Brassica rapa [45]. The experiment showed that $A B A$ can stimulate the expression levels of all three BrRZ proteins. During seed germination, the BrRZ3overexpressing mutant showed retarded seed germination and stem growth under normal growth conditions,

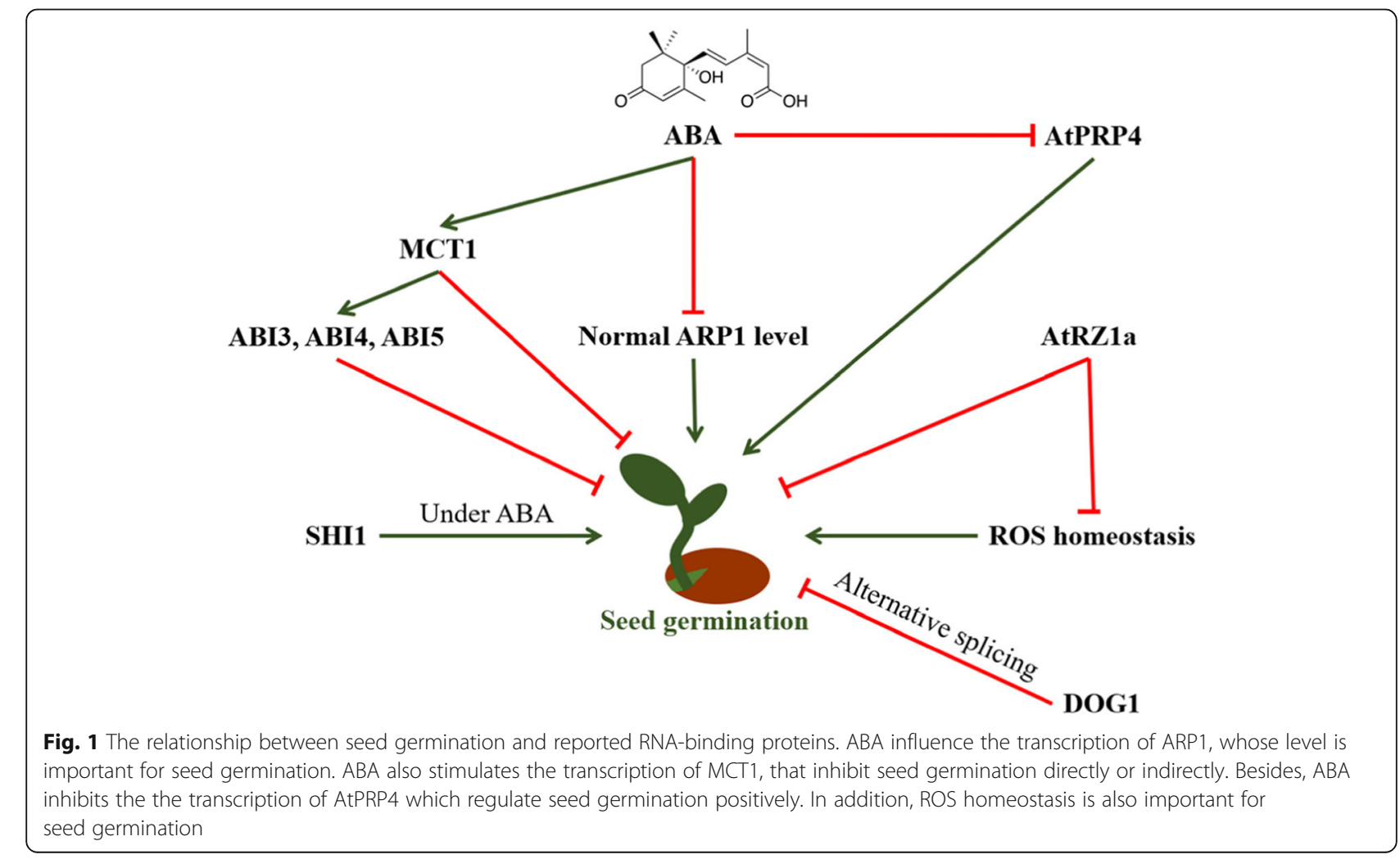


whereas it displayed decreased transcript levels of $\beta$-glucosidase (BGU) and GA4 homology (GA4H) and increased levels of $L E A P$ and SSP in the presence of ABA. Germination of BrRZ2- or BrRZ3-overexpressing Arabidopsis seeds was delayed compared with that of wildtype seeds under dehydration, salt stress and cold stress conditions. Importantly, all BrRZs possessed RNA chaperone activity [45]. A previous report also indicated that RNA-binding proteins are involved in seed germination independent of ABA in Arabidopsis. SHINY1 (SHI1) is a K-homology domain-containing RNAbinding protein, and it interacts with CPL1 to regulate gene expression [46]. Jiang et al. (2013) reported that the shi1 mutant is more sensitive to cold conditions during Arabidopsis vegetative growth and is insensitive to ABA during seed germination [46]. SHI1 can interact with SHI4/CPL1. Loss-of-function mutations in shi1 and shi4 resulted in similar changes in the expression patterns of some stress-related genes. Moreover, both shil and shi4 mutants display higher mRNA capping efficiency and altered polyadenylation site selection for some of the stress-related genes [46]. Except dicots, in recent years, a lot of proteomic studies conducted in monocot have been conducted in exploring the gene expression regulation, reserves mobilization and metabolisms reactivation, which brings us new insights on the mechanisms of metabolism regulation during this process. In Oryza sativa, proteomic analysis revealed the existence of $\mathrm{KH}$ domain containing protein and a glycine-rich RNA-binding protein is important for seed germination. Decreased glycine-rich RNA-binding protein level after absorbing water in seeds appear to be associated with seed germination [47]. Moreover, the glycine rich RNA-binding protein was down-regulated after seeds imbibition, which might promote germination. They supposed that the RNA-binding proteins probably involved in RNA stability by forming RNA chaperones during seed germination. In addition, the RNA-binding proteins play important role in keeping the stability and regulating the functions of the long-lived mRNAs, which was shown more than 17,000 stored mRNAs exist in dry rice seeds by previous study [48].

Collectively, these findings suggest a finely controlled but crucial role of RNA-binding proteins during germination. So far, how these activities are regulated in a coordinated and sequential manner is largely unknown. Moreover, other germination related RNAbinding proteins need to be discovered and studied in the future.

\section{Seed germination and miRNA}

miRNAs are a small non-coding RNA molecule which participates in RNA silencing and post-transcriptional regulation of gene expression through mRNA cleavage or repressing translation [49-52]. In plants, miRNAs participate in a broad range of important seed related processes, including seed development, seed dormancy, seed germination [53]. By exploring the mechanism of seed germination, a variety of miRNAs which involved in phytohormone signaling responses, stress responses, antioxidant effect and regulation of key transcription factors have been identified, and are considered to play an important role in seed germination [54, 55]. Numerous miRNAs are present in the germinating seeds of Arabidopsis, some of which are involved in the regulation of germination by phytohormones, such as abscisic acid (ABA) and auxin. In plants, miRNAs can interact with $\mathrm{ABA}$, an important germination regulator, to regulate seed germination. Reyes and Chua (2007) showed that in germinating Arabidopsis seeds, ABA induces the accumulation of mature miRNA159 in an ABI3dependent way, and the miRNA159 mediates cleavage of the MYB101 and MYB33 transcripts (Table 1) [56]. These two MYB transcription factors function as positive regulators of $\mathrm{ABA}$ responses, and the knockdown mutants of myb33 and myb101 show hyposensitivity to ABA. Furthermore, the miRNA159 over-expression mutant had reduced MYB33 and MYB101 transcript levels that rendered the plants hyposensitive to ABA. In addition, the accumulation of miRNA159 in the abi3 mutant was reduced 2- to 3 -fold with respect to that of wild type, indicating that ABI3 regulates miRNA159 expression [56]. Moreover, at higher ABA concentrations, the germination efficiency of the miRNA159-overexpressing mutant seeds was higher than the wild type seeds under the same conditions. This result suggested that the ABA-induced accumulation of miRNA159 is a homeostatic mechanism to induce MYB33 and MYB101

Table 1 The type and sequence of seed germination related microRNA

\begin{tabular}{llll}
\hline miRNA & Sequence $\left(\mathbf{5}^{\prime}\right.$-3') & Target genes & References \\
\hline miRNA159 & UUUGGAUUGAAGGGAGUCUA & MYB33, MYB101 & [56] \\
miRNA402 & UUCGAGGCCUAUUAAACCUCUG & DML3 & [57] \\
miRNA160 & UGCCUGGCUCCCUGUAUGCCA & ARF10, ARF16, ARF17 & [58] \\
miRNA395c & CUGAAGUGUUUGGGGGACUC & Unknown & {$[57]$} \\
miRNA395e & CUGAAGUGUUUGGGGGACUC & APS, SULTR2;1 & {$[57]$} \\
miRNA163 & UUGAAGAGGACUUGGACUUCGAU & PXMT1 & {$[59]$} \\
\hline
\end{tabular}


transcript degradation, which desensitizes the seed to ABA signaling during seed germination [56]. Besides, the functional roles of miRNA402 in Arabidopsis were also investigated under stress conditions [57]. In Arabidopsis, ABA was shown to regulate DNA demethylation through DNA glycosylase [60, 61]. Kim et al. (2010a) indicated that a putative DNA glycosylase, DEMETERLIKE protein3 (DML3), which is involved in DNA demethylation, is the target of miRNA402 (Table 1) [57]. The expression of DEMETER-LIKE protein3 mRNA was downregulated in miRNA402-overexpressing transgenic plants. The transcript level of miRNA402 in the germinating seeds was significantly increased by dehydration, cold and salt, and the expression of the stress response markers $R D 29 A$ or $R D 29 B$ were significantly increased under these stresses. Moreover, 35S::miRNA402 seeds and $d m l 3$ mutant seeds germinated earlier than wildtype seeds under salt stress conditions. This finding implies that mature miRNA402 plays a role as a positive regulator of seed germination of Arabidopsis under stress conditions, and that miRNA402-guided regulation of DNA demethylation is an adaptive process of plants to stress conditions [57].

In addition to $\mathrm{ABA}$, auxin is also an important hormone that participates in seed germination. AUXIN RESPONSE FACTORS (ARFs) are transcription factors involved in auxin signal transduction [62]. By using derepression experiments wherein silent mutations are introduced into the ARF10 sequence complementary to miRNA160, Liu et al. (2007) showed that negative regulation of ARF10 by miRNA160 plays important roles in seed germination [58]. Transgenic plants expressing an miRNA160-resistant form of ARF10 exhibited developmental defects such as curled stems, serrated leaves, and contorted flowers. During germination, the transgenic mutant seeds were hypersensitive to ABA in a dosedependent manner. In contrast, overexpression of miRNA160 resulted in reduced sensitivity to ABA during germination. In line with that, Nonogaki (2008) also indicated that miRNA160 could influence seed germination by targeting ARF16 and ARF17 in Arabidopsis [63]. In addition, the expression of sulfate metabolismrelated enzymes is also regulated by miRNAs during seed germination. Kim et al. (2010b) showed that the transgenic Arabidopsis miRNA395c-overexpressing mutant and the miRNA395e-overexpressing mutant have negative and positive effects on the seed germination of Arabidopsis, respectively, under salt or dehydration stress conditions [64]. This result indicated that germination of the miRNA395c-overexpressing mutant was significantly retarded compared with that of the wild type. In contrast, seed germination of the miRNA395eoverexpressing mutant was noticeably accelerated under salt or dehydration stress. Further analysis during seed germination showed that the mRNA cleavage of ATP sulfurylase (APS) and the sulfate transporter SULTR2;1 were mediated by the mature miRNA395e [64].

Recently, Chung et al. (2016) showed that light can regulate seed germination through influencing the expression of miRNA163 [59]. In Arabidopsis, miRNA163 is 24 nucleotides in length, and it targets the transcripts encoding S-adenosyl-Met-dependent carboxyl methyltransferase (SAMT)-like proteins [59]. Chung et al. (2016) also showed that primary miRNA163 levels increased significantly under light. In contrast, the transcript levels of PXMT1, the target of miRNA163 that encodes a methyltransferase that methylates 1,7-paraxanthine, decreased under the same light conditions. Moreover, during seed germination, miRNA163 and its target PXMT1 are predominantly expressed in the radicle, and mirna163 knockout mutant or PXMT1-overexpressing mutant showed delayed seed germination compared with the wild type under continuous light [59].

Various reports have also shown that miRNA and seed germination have complex regulatory networks in other plants. Huang et al. (2013) performed a comprehensive analysis of miRNAs during seed maturation in Brassica napus through using whole seeds and separate analyses [65]. Their study identified more than 500 conserved miRNA or variant unique sequences. The miRNA156 family was the most abundant in the seed followed by the miRNA159, miRNA172, miRNA167 and miRNA158 families. The functional classification revealed that their target genes were highly enriched in pathways of RNA, DNA, protein, S-assimilation, development, signaling and redox. Detailed inspection of the results revealed that some miRNAs function in the same pathway(s) by targeting different genes in the same family. In addition, they also predicted that miRNA173, miRNA400 and miRNA396 "cotarget" pentatricopeptide (PPR) repeatcontaining proteins, which indicated an interaction between RNA-binding proteins and miRNA during seed germination. In addition, F-box family proteins are cotargets of miRNA156, miRNA394 and miRNA319.

Auxin response factors (ARFs) could be regulated by miRNA160, miRNA167, miRNA390 and miRNA156 coordinately [65]. In line with this, Jian et al. (2016) also suggested an important role of miRNA156 during seed germination of Brassica napus [66]. They constructed three small-RNA libraries from Brassica napus exposed to distilled water, drought, and salt during imbibition of the seed. The results indicated that under the distilled water, drought, and salt conditions, 85, 81, and 81 known miRNAs were found, respectively. miRNA156 showed the highest abundance, followed by miRNA167, miRNA166, and miRNA390, during the early stage of seed germination under salt and drought stresses [66]. Under drought conditions, miRNA156, miRNA169, 
miRNA860, miRNA399, miRNA171, and miRNA395 were significantly downregulated, whereas only miRNA172 was significantly upregulated. In contrast, only two miRNA families, miRNA393 and miRNA399, were significantly downregulated under salt stress. Moreover, droughtresponsive family protein (DRRP), early responsive to dehydration stress protein (ERD), stress-responsive alphabeta barrel domain protein (SRAP), and salt tolerance homolog2 (STH2) were confirmed as the targets of the identified miRNAs. Besides, the prediction of the identified miRNA showed that various transcription factors (including SBP, MYB, ARF, NAC, TCP, NF-YA, GRF) and metabolic process related proteins (such as F-box protein, ATP sulfurylase, CCHC-type zinc finger protein, NAD(P)binding protein, ADP-ribose polymerase), were identified as conserved miRNA targets [66]. In Nelumbo nucifera, by using high-throughput small RNA sequencing, $\mathrm{Hu}$ et al. (2016) identified 145 known miRNAs and 78 novel miRNAs during seed germination. The largest miRNA family size identified was miRNA396, following by miRNA169 and miRNA393 possessed 12 and 8 members, respectively [67]. They also detected 2580 targets were detected for all the miRNAs by using degradome sequencing. Furthermore, both miRNA159b and miRNA319c targeted mRNA encoding the MYB transcription factor. miRNA156a, miRNA160a, miRNA160a-5p and miRNA169a targeted mRNA encoding many transcription factors, including SPL17, ARF18, NAC, NF-YA10. GO (Gene Ontology) and KEGG pathway analyses of the putative target genes showed that many target genes enriched in "regulation of transcription" and involved in "carbohydrate metabolism", "amino acid and energy metabolism" [67].

In monocots, some studies also explored the regulatory mechanisms between miRNAs and seed germination. Kang et al. (2012) carried out a miRNA microarray analysis to study the expression of conserved miRNAs in maize seeds and identified 125 known miRNAs [68]. Further study indicated that miRNA319 had a significant influence on seed germination. Moreover, miRNA171 and miRNA166 also played important roles in seed germination. miRNA166 was predicted to target bZIP genes in maize [69], which could regulate many processes such as seed maturation and stress signaling [70]. miRNA171 was predicted to target the GRAS transcription factor that controlled gibberellic acid (GA) signaling and phytochrome A signal transduction in seeds [71]. He et al. (2015) carried out an experiment to explore the regulation mechanism of miRNA in the first $24 \mathrm{~h}$ after imbibition which is important for rice seed germination [72]. The analysis identified 289 miRNA loci, including 59 known and 230 novel miRNAs. Moreover, 17 conserved families were detected in the imbibed rice seeds, and miRNA319, miRNA168, miRNA156, miRNA166, and miRNA159 had high abundance after imbibition. However, some conserved miRNAs, i.e., miRNA164, miRNA395, and miRNA393, were lowly expressed in rice seeds. Besides, they also demonstrated that miRNA160, miRNA156/miRNA529, miRNA319 and miRNA159 can regulate seed germination by targeting the mRNAs coding ARFs, SPL, TCP, MYB transcription factors respectively [72].

\section{Alternative splicing}

Alternative splicing is a finely regulated process during gene expression that leads to a single gene coding for multiple proteins. The interaction between seed germination and alternative splicing has been originally studied in Arabidopsis. A genomic study on ABA-regulated gene expression was performed to identify 1354 ABAresponsive genes and novel ABA signaling components $[73,74]$. To further determine whether the splicingrelated genes that encode small nuclear ribonucleoprotein particle (snRNP) proteins are regulated by ABA, Raab and Hoth (2007) analyzed the transcript abundances of genes that encode snRNPs using the ASRG database [75]. Their results suggested that an ABAdependent repression was found for $25 \%$ of the 91 snRNP genes that indicated changed splicing activity in the presence of ABA. Moreover, the U4/U6-specific snRNP gene AtPRP4 was repressed by ABA. The knockout of AtPRP4 displayed retarded seed germination, suggesting that alternative splicing is crucial for Arabidopsis seed germination [75]. In recent years, increasing numbers of studies have investigated alternative gene splicing during seed germination. The Arabidopsis protein DOG1 (DELAY OF GERMINATION 1) is an important effector of seed dormancy. It was originally identified through QTL and the DOG1 locus shows sequence variation in both the promoter and coding region among its accessions [76]. Moreover, the variation in DOG1 expression contributes to variations in seed dormancy levels [76]. Nakabayashi et al. (2015) showed that the DOG1 gene is alternatively spliced during breakage of seed dormancy [77]. In their study, they indicated that the DOG1 gene produces five transcript variants encoding three protein isoforms. The seeds of $\operatorname{dog} 1$ mutant only transcripts single DOG1 variants, and do not accumulate DOG1 protein. Further analysis showed that expressing two or more DOG1 transcript variants can lead to late germination and high accumulation level of DOG1 protein [77]. Moreover, DOG1 protein can bind to itself, and different DOG1 variant contained Arabidopsis seeds show different seed dormancy level. This finding suggests that the accumulation of DOG1 protein requires the presence of multiple isoforms. Interestingly, their study also indicated that the single isoforms are functional but require the presence of additional isoforms to prevent protein degradation [77]. 
In addition, Zhang et al. (2016) conducted RNAsequencing experiments to dissect alternative splicing events in barley seed germination and once again emphasized the important role of alternative splicing in seed germination [78]. Their results identified between 552 and 669 common alternative splicing transcripts in germinating barley embryos from four barley varieties. Alternative 3' splicing (34-45\%), intron retention (32$34 \%)$ and alternative $5^{\prime}$ splicing (16-21\%) were three major alternative splicing events during seed germination [78]. The KEGG pathway analysis showed that alternative splicing transcripts were predominantly mapped onto ribosome, RNA transport, spliceosome, oxidative phosphorylation, mRNA surveillance, protein synthesis, glycolysis, carbon metabolism, spliceosome. They also showed that auxin efflux carrier and SnRK2 were alternatively spliced during germination [78]. Moreover, correlation analysis of gene expression supported that alternative splicing of hormone responsive transcripts could coexist with gene transcripts responsible for protein biosynthesis and sugar metabolism, which revealed an important role of alternative splicing in barley seed germination [78]. Recently, Tognacca et al. (2019) carried out an experiment to study the effect of alternative splicing on the expression of light related genes during Arabidopsis seed germination. They evaluated transcriptome-wide changes in stratified seeds irradiated with a pulse of red light or far-red light. They showed that the red light changed the expression of $20 \%$ of the transcriptome and modified the alternative splicing pattern of 226 genes associated with a strong enrichment in the GO categories of mRNA processing, RNA splicing, and mRNA metabolic processes [79]. Furthermore, the experiment confirmed that red light controls the expression of alternative splicing related factors (At-SR30, At-RS31a, At-RS31, and At-U2AF65A), a light-signaling component (At-PIF6), and a dormancyrelated gene (At-DRM1). Therefore, based on those result, they conclude that red light triggers alternative splicing changes in some splicing factors, phytochrome $\mathrm{B}$, light-signaling components, and dormancy/germination regulators [79].

\section{Conclusions}

Seed germination is a series of orderly physiological processes and morphogenetic processes from the beginning of seed swelling. It is also a complex process involving multiple levels of regulation $[1,4]$. In plants, post-

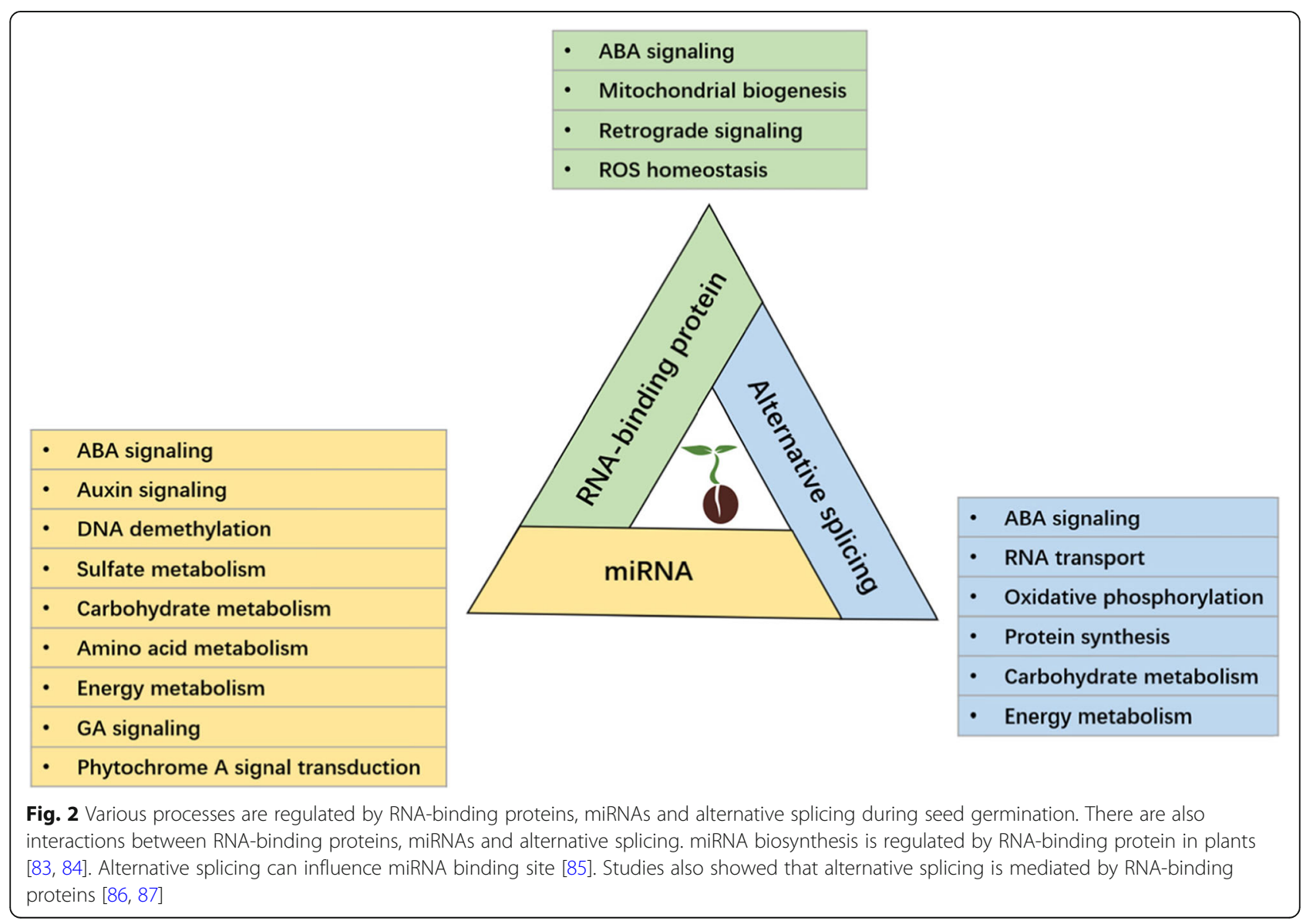


transcriptional regulation is an essential and important component of gene expression regulation. Numerous findings have unveiled and characterized various factors involved in post-transcriptional regulation, such as RNA-binding proteins, poly (A)-binding proteins (PABPs), miRNAs, lncRNAs, and snRNAs [9, 80-82]. Considering the tight and complex connection between post-transcriptional regulation and seed germination (Fig. 2), it will be interesting to discover the new mechanisms of post-transcriptional regulation in seed germination. Some recently developed technologies will assist with future studies. In addition, there are still many aspects of RNA decay that need to be studied deeply, such as the spliceosome and editosome (a large multiprotein complex that catalyzes RNA editing) that have a crucial role in post-transcriptional regulation. Thorough knowledge of the regulatory mechanisms of RNA-binding proteins and miRNAs during seed germination are scarce, taking into consideration their high numbers in plants. Recent studies have found that mRNA stability and oxidation are involved in the regulation of seed germination, and the completion of germination and the regulation of dormancy also depend on the degradation of specific subsets of mRNA, indicating a tight relationship at work between seed germination and post-transcriptional regulation [88-91]. In addition, post-translational regulation and protein modification also participates in the regulation of seed germination, such as mRNA decapping, protein phosphorylation, protein oxidation [92-95].

Here, we addressed many important connections between seed germination and post-transcriptional regulatory factors in plants, including RNA-binding proteins, miRNAs and alternative splicing. These findings may inspire us to investigate new regulatory mechanisms and to fill in the gaps in knowledge regarding the interactions between seed germination and post-transcriptional regulation in plants.

In conclusion, post-transcriptional regulation has attracted consideration in seed germination related processes. More work needs to be carried out to understand the functions and mechanisms related to the involvement of post-transcriptional regulation in germinationrelated processes. This kind of new knowledge could also pave the way for discovering a new and complex regulatory seed germination network in plants, and the new findings will provide new research directions for seed biology and enrich the field of seed germination.

\section{Abbreviations}

RBPS: RNA-binding proteins; RRM: RNA recognition motif; NMD: nonsense mediated decay; KH: K-homology; PPR: pentatricopeptide-repeat; ARP1: ABAREGULATED RNA-BINDING PROTEIN 1; MCT1: MEI2 C-TERMINAL RRM ONLY LIKE 1; GRP2: GLYCINE RICH PROTEIN 2; ISO: isocitrate lyase; CRU: cruciferin; SSP: 125 seed storage protein; LEAP: LEA protein in group five; BGU: $\beta$ glucosidase; GA4H: GA4 homology; SHI1: SHINY1; DML3: DEMETER-LIKE protein3; ARFs: AUXIN RESPONSE FACTORS; APS: ATP sulfurylase; DRRP: drought-responsive family protein; ERD: dehydration stress protein; SRAP: stress-responsive alpha-beta barrel domain protein; STH2: salt tolerance homolog2; DOG1: DELAY OF GERMINATION 1

\section{Acknowledgements \\ Not applicable.}

\section{Authors' contributions}

All the authors significantly contributed to this research paper. M.W. supervised this work. M.W, F.J. and X.X. wrote the manuscript. S.D., M.X., A.W., J.C. contributed to the organization of the manuscript and miRNA part. M.W., H.X., X.Z., Q.J., Y.Z. contributed to the background part, conclusion part and help to revise the manuscript. All authors have read and approved the manuscript.

\section{Funding}

All the authors and this article was supported by Talent Introduction Special Funds of Qingdao Agricultural University (663/1120070) and The Taishan Scholars Program (tsqn201909134). The funders had no role in the experimental design, data collection and analysis or writing of the manuscript.

\section{Availability of data and materials}

Data sharing is not applicable to this article as no datasets were generated or analysed during the current study.

\section{Declarations}

Ethics approval and consent to participate

Not applicable.

Consent for publication

Not applicable.

\section{Competing interests}

The authors declare that they have no competing interests.

\section{Author details}

${ }^{1}$ College of Agronomy, Qingdao Agricultural University, Qingdao 266109, China. ${ }^{2}$ Dryland-Technology Key Laboratory of Shandong Province, Qingdao Agricultural, Qingdao 266109, China. ${ }^{3}$ Administrative Committee of Yellow River Delta Agri-High-Tech Industry Demonstration Zone, Dongying 257347, China.

${ }^{4}$ Shandong Institute of Pomology, Tai'an 271000, China. ${ }^{5}$ Jinan Fruit Research Institute, All China Federation of Supply and Marketing Co-operatives, Jinan 250000, China. ${ }^{6}$ Shandong Academy of Agricultural Sciences, Jinan 250000, China.

Received: 28 September 2020 Accepted: 7 April 2021

Published online: 21 April 2021

\section{References}

1. Han C, Yang P. Studies on the molecular mechanisms of seed germination. Proteomics. 2015;15(10):1671-9. https://doi.org/10.1002/pmic.201400375.

2. Steinbrecher $T$, Leubner-Metzger $G$. The biomechanics of seed germination. J Exp Bot. 2017;68(4):765-83. https://doi.org/10.1093/jxb/erw428.

3. Nonogaki H, Bassel GW, Bewley JD. Germination-still a mystery. Plant Sci. 2010;179(6):574-81. https://doi.org/10.1016/j.plantsci.2010.02.010.

4. Duval M, Gallardo K, Catusse J, Bally J. Seed germination and vigor. Annu Rev Plant Biol. 2012;63(1):507-33.

5. Hoyle GL, Steadman KJ, Good RB, McIntosh EJ, Galea LM, Nicotra AB. Seed germination strategies: an evolutionary trajectory independent of vegetative functional traits. Front Plant Sci. 2015:6:731.

6. Shu K, Liu XD, Xie Q, He ZH. Two faces of one seed: hormonal regulation of dormancy and germination. Mol Plant. 2016;9(1):34-45. https://doi.org/10.1 016/j.molp.2015.08.010.

7. Penfield S. Seed dormancy and germination. Curr Biol. 2017;27(17):R874-8. https://doi.org/10.1016/j.cub.2017.05.050.

8. Chmielowskabak J, Arasimowiczjelonek M, Deckert J. In search of the mRNA modification landscape in plants. BMC Plant Biol. 2019;19(1). 
9. Romanowski A, Yanovsky MJ. Circadian rhythms and post-transcriptional regulation in higher plants. Front Plant Sci. 2015;6:437.

10. Szweykowska-Kulinska Z, Jarmolowski A. Post-transcriptional regulation of MicroRNA accumulation and function: new insights from plants. Mol Plant. 2018;11(8):1006-7. https://doi.org/10.1016/j.molp.2018.06.010.

11. Joshna CR, Saha P, Atugala D, Chua G, Muench DG, Plant PUF. RNA-binding proteins: a wealth of diversity for post-transcriptional gene regulation. Plant Sci. 2020:110505.

12. Guerra D, Crosatti C, Khoshro HH, Mastrangelo AM, Mica E, Mazzucotelli E. Post-transcriptional and post-translational regulations of drought and heat response in plants: a spider's web of mechanisms. Front Plant Sci. 2015;6:57.

13. Budak H, Akpinar BA. Plant miRNAs: biogenesis, organization and origins. Funct Integr Genomic. 2015;15(5):523-31.

14. Samad AF, Sajad M, Nazaruddin N, Fauzi IA, Murad A, Zainal Z, et al. MicroRNA and transcription factor: key players in plant regulatory network. Front Plant Sci. 2017;8:565.

15. Brant EJ, Budak H. Plant small non-coding RNAs and their roles in biotic stresses. Front Plant Sci. 2018;9:1038. https://doi.org/10.3389/fpls.2018.01038.

16. Marondedze C, Thomas L, Serrano NL, Lilley KS, Gehring C. The RNA-binding protein repertoire of Arabidopsis thaliana. Sci Rep-UK. 2016;6(1):29766. https://doi.org/10.1038/srep29766.

17. Hentze MW, Castello A, Schwarzl T, Preiss T. A brave new world of RNAbinding proteins. Nat Rev Mol Cell Bio. 2018;19(5):327.

18. Brosnan CA, Sarazin A, Lim P, Bologna NG, Hirsch-Hoffmann M, Voinnet O. Genome-scale, single-cell-type resolution of microRNA activities within a whole plant organ. The EMBOJ. 2019;38(13).

19. Zhang B. MicroRNA: a new target for improving plant tolerance to abiotic stress. J Exp Bot. 2015;66(7):1749-61. https://doi.org/10.1093/jxb/erv013.

20. Liu WW, Meng J, Cui J, Luan YS. Characterization and function of microRNA* S in plants. Front Plant Sci. 2017;8:2200. https://doi.org/10.3389/ fpls.2017.02200.

21. Wilkinson ME, Charenton C, Nagai K. RNA splicing by the Spliceosome. Annu Rev Biochem. 2020;89(1):359-88. https://doi.org/10.1146/annurevbiochem-091719-064225.

22. Li Y, Xia C, Feng J, Yang D, Wu F, Cao Y, et al. The SNW domain of SKIP is required for its integration into the spliceosome and its interaction with the Paf1 complex in Arabidopsis. Mol Plant. 2016;9(7):1040-50. https://doi.org/1 0.1016/j.molp.2016.04.011.

23. Kesarwani AK, Lee HC, Ricca PG, Sullivan G, Faiss N, Wagner G, et al. Multifactorial and species-specific feedback regulation of the RNA surveillance pathway nonsense-mediated decay in plants. Plant Cell Physiol. 2019;60(9):1986-99. https://doi.org/10.1093/pcp/pcz141.

24. Lorković ZJ. Role of plant RNA-binding proteins in development, stress response and genome organization. Trends Plant Sci. 2009;14(4):229-36. https://doi.org/10.1016/j.tplants.2009.01.007.

25. Ambrosone A, Costa A, Leone A, Grillo S. Beyond transcription: RNAbinding proteins as emerging regulators of plant response to environmental constraints. Plant Sci. 2012;182:12-8. https://doi.org/10.1 016/j.plantsci.2011.02.004.

26. Lee $\mathrm{K}$, Kang $\mathrm{H}$. Emerging roles of RNA-binding proteins in plant growth, development, and stress responses. Mol Cells. 2016;39(3):179-85. https://doi. org/10.14348/molcells.2016.2359.

27. Wang M, Ogé L, Perez-Garcia MD, Hamama L, Sakr S. The PUF protein family: overview on PUF RNA targets, biological functions, and post transcriptional regulation. Int J Mol Sci. 2018;19(2):410. https://doi.org/10.33 90/ijms19020410.

28. Narsai R, Law SR, Carrie C, Xu L, Whelan J. In-depth temporal transcriptome profiling reveals a crucial developmental switch with roles for RNA processing and organelle metabolism that are essential for germination in Arabidopsis. Plant Physiol. 2011;157(3):1342-62. https://doi.org/10.1104/ pp.111.183129.

29. Schmitz-Linneweber C, Small I. Pentatricopeptide repeat proteins: a socket set for organelle gene expression. Trends Plant Sci. 2008;13(12):663-70 https://doi.org/10.1016/j.tplants.2008.10.001.

30. Arc E, Sechet J, Corbineau F, Rajjou L, Marion-Poll A. ABA crosstalk with ethylene and nitric oxide in seed dormancy and germination. Front Plant Sci. 2013;4:63

31. Jung $\mathrm{HJ}$, Kim MK, Kang $\mathrm{H}$. An ABA-regulated putative RNA-binding protein affects seed germination of Arabidopsis under ABA or abiotic stress conditions. J Plant Physiol. 2013;170(2):179-84. https://doi.org/10.1016/j. jplph.2012.09.002.
32. Gu L, Jung HJ, Kwak KJ, Dinh SN, Kim YO, Kang H. An RRM-containing mei2like MCT1 plays a negative role in the seed germination and seedling growth of Arabidopsis thaliana in the presence of ABA. Plant Physiol Bioch. 2016;109:273-9. https://doi.org/10.1016/j.plaphy.2016.10.009.

33. Wang $Y$, Li L, Ye T, Zhao S, Liu Z, Feng YQ, et al. Cytokinin antagonizes ABA suppression to seed germination of Arabidopsis by downregulating ABI5 expression. Plant J. 2011;68(2):249-61. https://doi.org/10.1111/j.13 65-313X.2011.04683.X.

34. Feng CZ, Chen Y, Wang C, Kong YH, Wu WH, Chen YF. Arabidopsis RAV1 transcription factor, phosphorylated by SnRK2 kinases, regulates the expression of $A B|3, A B| 4$, and $A B \mid 5$ during seed germination and early seedling development. Plant J. 2014;80(4):654-68. https://doi.org/10.1111/tpj.12670.

35. Albertos P, Romero-Puertas MC, Tatematsu K, Mateos I, Sánchez-Vicente I, Nambara $\mathrm{E}$, et al. S-nitrosylation triggers ABI5 degradation to promote seed germination and seedling growth. Nat Commun. 2015;6(1):1-10.

36. Huang X, Zhang X, Gong Z, Yang S, Shi Y. ABI4 represses the expression of type-a ARRs to inhibit seed germination in Arabidopsis. Plant J. 2017;89(2): 354-65. https://doi.org/10.1111/tpj.13389.

37. Huang $Y$, Sun $M, Y e ~ Q$, Wu X, Wu W, Chen Y. Abscisic acid modulates seed germination via ABA INSENSITIVE5-mediated PHOSPHATE1. Plant Physiol. 2017;175(4):1661-8. https://doi.org/10.1104/pp.17.00164.

38. Nin S, Petrucci WA, Del Bubba M, Ancillotti C, Giordani E. Effects of environmental factors on seed germination and seedling establishment in bilberry (Vaccinium myrtillus L.). Sci Hortic-Amsterdam. 2017;226:241-9.

39. Yamaguchi S, Kamiya $Y$, Nambara E. Regulation of ABA and GA levels during seed development and germination in Arabidopsis. Annual Plant Rev. 2018: 224-47. https://doi.org/10.1002/9781119312994.apr0283.

40. Kim $\mathrm{YO}$, Pan $\mathrm{S}$, Jung $\mathrm{CH}$, Kang $\mathrm{H}$. A zinc finger-containing glycine-rich RNAbinding protein, atRZ-1a, has a negative impact on seed germination and seedling growth of Arabidopsis thaliana under salt or drought stress conditions. Plant Cell Physiol. 2007;48(8):1170-81. https:/doi.org/10.1093/pcp/pcm087.

41. Fusaro AF, Bocca SN, Ramos RLB, Barrôco RM, Magioli C, Jorge VC, et al. AtGRP2, a cold-induced nucleo-cytoplasmic RNA-binding protein, has a role in flower and seed development. Planta. 2007;225(6):1339-51. https://doi. org/10.1007/s00425-006-0444-4

42. Yang DH, Kwak KJ, Kim MK, Park SJ, Yang KY, Kang H. Expression of Arabidopsis glycine-rich RNA-binding protein AtGRP2 or AtGRP7 improves grain yield of rice (Oryza sativa) under drought stress conditions. Plant Sci. 2014;214:106-12. https://doi.org/10.1016/j.plantsci.2013.10.006.

43. Baek D, Cha JY, Kang S, Park B, Lee HJ, Hong H, et al. The Arabidopsis a zinc finger domain protein ARS1 is essential for seed germination and ROS homeostasis in response to $\mathrm{ABA}$ and oxidative stress. Front Plant Sci. 2015:6:963.

44. Bi C, Ma Y, Wu Z, Yu YT, Liang S, Lu K, et al. Arabidopsis ABI5 plays a role in regulating ROS homeostasis by activating CATALASE 1 transcription in seed germination. Plant Mol Biol. 2017;94(1-2):197-213. https://doi.org/10.1007/ s11103-017-0603-y.

45. Park YR, Choi MJ, Park SJ, Kang H. Three zinc-finger RNA-binding proteins in cabbage (Brassica rapa) play diverse roles in seed germination and plant growth under normal and abiotic stress conditions. Physiol Plantarum. 2017; 159(1):93-106.

46. Jiang J, Wang B, Shen Y, Wang H, Feng Q, Shi H. The Arabidopsis RNA binding protein with $\mathrm{K}$ homology motifs, SHINY1, interacts with the $\mathrm{C}$ terminal domain phosphatase-like 1 (CPL1) to repress stress-inducible gene expression. PLoS Genet. 2013;9(7).

47. Masaki S, Yamada T, Hirasawa T, Todaka D, Kanekatsu M. Proteomic analysis of RNA-binding proteins in dry seeds of rice after fractionation by ssDNA affinity column chromatography. Biotechnol Lett. 2008;30(5):955-60. https:// doi.org/10.1007/s10529-007-9619-8.

48. Howell KA, Narsai R, Carroll A, Ivanova A, Lohse M, Usadel B, et al. Mapping metabolic and transcript temporal switches during germination in rice highlights specific transcription factors and the role of RNA instability in the germination process. Plant Physiol. 2009;149(2):961-80. https://doi.org/10.11 04/pp.108.129874

49. Li C, Zhang B. MicroRNAs in control of plant development. J Cell Physiol. 2016:231(2):303-13. https://doi.org/10.1002/jcp.25125.

50. Bartel DP. Metazoan micrornas. Cell. 2018;173(1):20-51. https://doi.org/10.1 016/j.cell.2018.03.006.

51. Song X, Li Y, Cao X, Qi Y. MicroRNAs and their regulatory roles in plantenvironment interactions. Annu Rev Plant Biol. 2019:70(1):489-525. https:// doi.org/10.1146/annurev-arplant-050718-100334. 
52. Meyers BC, Axtell MJ. MicroRNAs in plants: key findings from the early years. Plant Cell. 2019;31(6):1206-7. https://doi.org/10.1105/tpc.19.00310.

53. Liu H, Yu H, Tang G, Huang T. Small but powerful: function of microRNAs in plant development. Plant Cell Rep. 2018;37(3):515-28. https://doi.org/10.1 007/s00299-017-2246-5.

54. Martin RC, Liu PP, Nonogaki $H$. Simple purification of small RNAs from seeds and efficient detection of multiple microRNAs expressed in Arabidopsis thaliana and tomato (Lycopersicon esculentum) seeds. Seed Sci Res. 2005; 15(4):319-28. https://doi.org/10.1079/SSR2005220.

55. Martin RC, Liu PP, Nonogaki H. microRNAs in seeds: modified detection techniques and potential applications. Botany. 2006;84(2):189-98.

56. Reyes $J$, Chua NH. ABA induction of miR159 controls transcript levels of two MYB factors during Arabidopsis seed germination. Plant J. 2007;49(4): 592-606. https://doi.org/10.1111/j.1365-313X.2006.02980.x.

57. Kim JY, Kwak KJ, Jung HJ, Lee HJ, Kang H. MicroRNA402 affects seed germination of Arabidopsis thaliana under stress conditions via targeting DEMETER-LIKE Protein3 mRNA. Plant Cell Physiol. 2010a;51(6):1079-83. https://doi.org/10.1093/pcp/pcq072.

58. Liu PP, Montgomery TA, Fahlgren N, Kasschau KD, Nonogaki H, Carrington JC. Repression of AUXIN RESPONSE FACTOR10 by microRNA160 is critical for seed germination and post-germination stages. Plant J. 2007:52(1):133-46. https://doi.org/10.1111/j.1365-313X.2007.03218.x.

59. Chung PJ, Park BS, Wang H, Liu J, Jang IC, Chua NH. Light-inducible miR163 targets PXMT1 transcripts to promote seed germination and primary root elongation in Arabidopsis. Plant Physiol. 2016;170(3):1772-82. https://doi. org/10.1104/pp.15.01188.

60. Zhu JK. Active DNA demethylation mediated by DNA glycosylases. Annu Rev Genet. 2009;43(1):143-66. https://doi.org/10.1146/annurev-genet-1021 08-134205.

61. Kim JS, Lim JY, Shin H, Kim BG, Yoo SD, Kim WT, et al. ROS1-dependent DNA demethylation is required for ABA-inducible NIC3 expression. Plant Physiol. 2019;179(4):1810-21. https://doi.org/10.1104/pp.18.01471.

62. Chandler JW. Auxin response factors. Plant Cell Environ. 2016;39(5):1014-28. https://doi.org/10.1111/pce.12662.

63. Nonogaki $H$. Repression of transcription factors by microRNA during seed germination and postgerminaiton: another level of molecular repression in seeds? Plant Signal Behav. 2008;3(1):65-7. https://doi.org/1 0.4161/psb.3.1.4918

64. Kim JY, Lee HJ, Jung HJ, Maruyama K, Suzuki N, Kang H. Overexpression of microRNA395c or 395e affects differently the seed germination of Arabidopsis thaliana under stress conditions. Planta. 2010b;232(6):1447-54. https://doi.org/10.1007/s00425-010-1267-x.

65. Huang D, Koh C, Feurtado JA, Tsang EW, Cutler AJ. MicroRNAs and their putative targets in Brassica napus seed maturation. BMC Genomics. 2013; 14(1):140. https://doi.org/10.1186/1471-2164-14-140.

66. Jian H, Wang J, Wang T, Wei L, Li J, Liu L. Identification of rapeseed microRNAs involved in early stage seed germination under salt and drought stresses. Front Plant Sci. 2016;7:658.

67. Hu J, Jin J, Qian Q, Huang K, Ding Y. Small RNA and degradome profiling reveals miRNA regulation in the seed germination of ancient eudicot Nelumbo nucifera. BMC Genomics. 2016;17(1):684. https://doi.org/10.1186/ s12864-016-3032-4

68. Kang $M$, Zhao Q, Zhu D, Yu J. Characterization of microRNAs expression during maize seed development. BMC Genomics. 2012;13(1):360. https://doi. org/10.1186/1471-2164-13-360.

69. Zhang L, Chia J, Kumari S, Stein J, Liu Z, Narechania A, et al. A genomewide characterization of microRNA genes in maize. PLoS Genet. 2009;5(11): e1000716. https://doi.org/10.1371/journal.pgen.1000716.

70. Jakoby M, Weisshaar B, Dröge-Laser W, Vicente-Carbajosa J, Tiedemann J, Kroj T, et al. bZIP transcription factors in Arabidopsis. Trends Plant Sci. 2002; 7(3):106-11. https://doi.org/10.1016/S1360-1385(01)02223-3.

71. Hirsch S, Oldroyd G. GRAS-domain transcription factors that regulate plant development. Plant Signal Behav. 2019;4(8):698. https://doi.org/10.4161/ psb.4.8.9176.

72. He D, Wang Q, Wang K, Yang P. Genome-wide dissection of the microRNA expression profile in rice embryo during early stages of seed germination. PLoS One. 2015;10(12)

73. Hoth S, Morgante M, Sanchez J, Hanafey MK, Tingey SV, Chua N. Genomewide gene expression profiling in Arabidopsis thaliana reveals new targets of abscisic acid and largely impaired gene regulation in the abi1-1 mutant. J Cell Sci. 2002;115(24):4891-900. https://doi.org/10.1242/jcs.00175.
74. Raab S, Toth Z, de Groot C, Stamminger T, Hoth S. ABA-responsive RNA binding proteins are involved in chloroplast and stromule function in Arabidopsis seedlings. Planta. 2006;224(4):900-14. https://doi.org/10.1007/ s00425-006-0282-4.

75. Raab S, Hoth S. A mutation in the AtPRP4 splicing factor gene suppresses seed development in Arabidopsis. Plant Biol. 2007;9(03):447-52. https://doi. org/10.1055/s-2006-924726.

76. Bentsink L, Jowett J, Hanhart CJ, Koornneef M. Cloning of DOG1, a quantitative trait locus controlling seed dormancy in Arabidopsis. P Natl Acad Sci. 2006;103(45):17042-7. https://doi.org/10.1073/pnas.0607877103.

77. Nakabayashi K, Bartsch M, Ding J, Soppe WJ. Seed dormancy in Arabidopsis requires self-binding ability of DOG1 protein and the presence of multiple isoforms generated by alternative splicing. PLoS Genet. 2015;11(12).

78. Zhang Q, Zhang X, Wang S, Tan C, Zhou G, Li C. Involvement of alternative splicing in barley seed germination. PloS one. 2016;11(3).

79. Tognacca RS, Servi L, Hernando CE, Saura-Sanchez M, Yanovsky MJ, Petrillo $\mathrm{E}$, et al. Alternative splicing regulation during light-induced germination of Arabidopsis thaliana seeds. Front Plant Sci. 2019;10:1076. https://doi.org/1 $0.3389 /$ fpls.2019.01076

80. Cuperus JT, Fahlgren N, Carrington JC. Evolution and functional diversification of MIRNA genes. Plant Cell. 2011;23(2):431-42. https://doi. org/10.1105/tpc.110.082784.

81. Gómez G, Pallás V. Viroids: a light in the darkness of the IncRNA-directed regulatory networks in plants. New Phytol. 2013;198(1):10-5. https://doi. org/10.1111/nph.12196.

82. Ohtani M. Transcriptional regulation of snRNAs and its significance for plant development. J Plant Res. 2017;130(1):57-66. https://doi.org/10.1007/s10265016-0883-3.

83. Ren G, Xie M, Dou Y, Zhang S, Zhang C, Yu B. Regulation of miRNA abundance by RNA binding protein TOUGH in Arabidopsis. P Natl Acad Sci. 2012;109(31):12817-21. https://doi.org/10.1073/pnas.1204915109.

84. Wu X, Shi Y, Li J, Xu L, Fang Y, Li X, et al. A role for the RNA-binding protein MOS2 in microRNA maturation in Arabidopsis. Cell Res. 2013;23(5):645-57. https://doi.org/10.1038/cr.2013.23.

85. Park SY, Grabau E. Bypassing miRNA-mediated gene regulation under drought stress: alternative splicing affects CSD1 gene expression. Plant Mol Biol. 2017;95(3):243-52. https://doi.org/10.1007/s11103-017-0642-4.

86. Schöning JC, Streitner C, Meyer IM, Gao Y, Staiger D. Reciprocal regulation of glycine-rich RNA-binding proteins via an interlocked feedback loop coupling alternative splicing to nonsense-mediated decay in Arabidopsis. Nucleic Acids Res. 2008;36(22):6977-87. https://doi. org/10.1093/nar/gkn847.

87. Bazin J, Romero N, Rigo R, Charon C, Blein T, Ariel F, et al. Nuclear speckle RNA binding proteins remodel alternative splicing and the non-coding Arabidopsis Transcriptome to regulate a cross-talk between Auxin and immune responses. Front Plant Sci. 2018;9:1209. https://doi.org/10.3389/ fpls.2018.01209.

88. Basbouss-Serhal I, Pateyron S, Cochet F, Leymarie J, Bailly C. 5' to 3' mRNA decay contributes to the regulation of Arabidopsis seed germination by dormancy. Plant Physiol. 2017;173(3):1709-23. https:// doi.org/10.1104/pp.16.01933.

89. El-Maarouf-Bouteau H, Meimoun P, Job C, Bailly C. Role of protein and mRNA oxidation in seed dormancy and germination. Front Plant Sci. 2013;4:77.

90. Gao F, Rampitsch C, Chitnis VR, Humphreys GD, Jordan MC, Ayele BT. Integrated analysis of seed proteome and mRNA oxidation reveals distinct post-transcriptional features regulating dormancy in wheat (Triticum aestivum L.). Plant Biotechnol J. 2013;11(8):921-32. https://doi.org/10.1111/ pbi.12083.

91. Bazin J, Langlade N, Vincourt P, Arribat S, Balzergue S, El-Maarouf-Bouteau H, et al. Targeted mRNA oxidation regulates sunflower seed dormancy alleviation during dry after-ripening. Plant Cell. 2011;23(6):2196-208. https:// doi.org/10.1105/tpc.111.086694

92. Job C, Rajjou L, Lovigny Y, Belghazi M, Job D. Patterns of protein oxidation in Arabidopsis seeds and during germination. Plant Physiol. 2005;138(2): 790-802. https://doi.org/10.1104/pp.105.062778.

93. Sajeev N, Bai B, Bentsink L. Seeds: a unique system to study translational regulation. Trends Plant Sci. 2019;24(6):487-95. https://doi.org/10.1016/j.tpla nts.2019.03.011.

94. Arc E, Galland M, Cueff G, Godin B, Lounifi I, Job D, et al. Reboot the system thanks to protein post-translational modifications and proteome diversity: 
how quiescent seeds restart their metabolism to prepare seedling establishment. Proteomics. 2011;11(9):1606-18. https://doi.org/10.1002/ pmic.201000641.

95. Yin X, Wang X, Komatsu S. Phosphoproteomics: Protein phosphorylation in regulation of seed germination and plant growth. Curr Protein Pept Sc. 2018;19(4):401-12.

\section{Publisher's Note}

Springer Nature remains neutral with regard to jurisdictional claims in published maps and institutional affiliations.

- fast, convenient online submission

- thorough peer review by experienced researchers in your field

- rapid publication on acceptance

- support for research data, including large and complex data types

- gold Open Access which fosters wider collaboration and increased citations

- maximum visibility for your research: over $100 \mathrm{M}$ website views per year

At $\mathrm{BMC}$, research is always in progress. 